\title{
Hearing Aid Use in Everyday Life: Managing Contextual Variability
}

\author{
Bettina Williger Frieder R. Lang \\ Institute of Psychogerontology, FAU Erlangen-Nürnberg, Nürnberg, Germany
}

\author{
Key Words \\ Hearing loss · Hearing impairment - Adaptive processes . \\ Hearing aids · Everyday activities
}

\begin{abstract}
Background and Objective: We investigated usage of and satisfaction with hearing aid devices in everyday life among older adults with hearing loss. Our research further advances the role of hearing contexts for hearing aid use and satisfaction. A central assumption was that hearing aid owners adapt the usage of the hearing aid devices to contextual demands of hearing depending on their personal resources. Methods: In a sample of 158 hearing aid owners aged 50-88 years, we examined proactive hearing aid use in everyday life and its association with the usage of, and satisfaction with, hearing aids. The study was administered online. Using an adapted version of the day-reconstruction method, participants reported hearing episodes during the preceding day. Hearing aid use was assessed via the proportion of waking time with hearing aids. Satisfaction with hearing aids was measured via the Satisfaction with Daily Amplification scale. Results: When using the hearing aids more often, and when reporting greater satisfaction, older adults indicated more diverse listening situations and experienced less variability in hearing quality with hearing aids. Conclusion: Our findings suggest that hearing aid owners may proactively use the hearing devices to master situation-specific de-
\end{abstract}

mands and difficulties in hearing quality. Such findings underline that hearing aid use and satisfaction depend on the extent to which the devices help to manage everyday life successfully.

(c) 2014 S. Karger AG, Basel

\section{Introduction}

Individual duration of hearing aid use and satisfaction with hearing aids varies. For example, Tesch-Römer [1] observed that daily hearing aid use ranges from 26 to 960 min. In the Blue Mountains Study [2], it was observed that $15 \%$ of hearing aid users wore the hearing devices less than $1 \mathrm{~h}$ per day, while most individuals (60\%) wore the devices $1-8 \mathrm{~h}$ per day, and $25 \%$ of all hearing aid owners wore their devices longer than $8 \mathrm{~h}$ daily. Response options allow less differentiation regarding satisfaction with hearing aids. In a Swiss survey of 7,891 hearing aid owners, $80 \%$ of participants were satisfied with their hearing aids [3]. In the EuroTrak I survey [4], 86\% of the French, 77\% of the British, and $72 \%$ of the German participants reported high satisfaction with their hearing aids.

It is a robust finding that individual differences in hearing aid use and satisfaction may depend on personal resources. For example, there is more frequent or longer hearing aid use when there is greater subjective awareness of one's hearing loss [5], stronger visual and fine motor

\section{KARGER 125}

(c) 2014 S. Karger AG, Basel

0304-324X/14/0612-0158\$39.50/0

E-Mail karger@karger.com

www.karger.com/ger 
skills [6], a higher cognitive capacity [7], more positive attitudes towards hearing aids [8], a stronger intention to use the devices [9], and when there is prior experience with hearing aids [5]. Comparable to correlates of hearing aid use, satisfaction with hearing aids is better when hearing aid owners are more aware of the hearing loss [10], and when there is prior experience with the hearing aids [11]. Besides, satisfaction with the devices is greater when users do not expect too much of the devices, are more agreeable, and are less neurotic [12].

In addition to personal resources, the demands of the listening environment (defined as the social, spatial, and auditory contexts) and the specific configuration of the hearing aid devices were found to relate to usage behaviour and satisfaction [13]. For example, Hartley et al. [2] found that hearing aid owners are less likely to use the hearing aids, when perceiving insufficient effectiveness, problems with amplification, and discomfort. Wong et al. [14], based on a review of the literature, reported that satisfaction with the hearing aids differs across diverse listening situations. For example, low-demand listening situations, such as conversations in quiet contexts, were associated with higher satisfaction scores compared to difficult listening situations such as conversations in noisy contexts (i.e. meetings or restaurant visits). Such findings illustrate that individual positive outcomes of hearing aid use may vary across contexts [15]. Little is known about how intra-individual variability and heterogeneity of everyday contexts account for the usage and evaluation of hearing aid devices.

Consequently, we addressed intra-individual variability in the usage and evaluation of hearing aids in everyday life. Our research is based on the assumption that hearing aid owners proactively use their devices in response to personal resources and contextual demands [15]. For example, older adults with hearing loss were observed to disengage from social contexts where they experience difficulty with hearing [16]. More generally, this selection of device use occurs in all everyday contexts. Individuals may not use hearing aids in demanding situations such as group conversation, or when watching TV with others. In a study on the adoption of information and communication technologies, Melenhorst et al. [17] observed that older adults are more likely to consider the benefits rather than the costs of technology use when deciding whether to use a technical device. In specific listening situations, the benefits of not using the hearing aids (i.e. no background noise, lower cognitive load) may outweigh the benefits of using it (i.e. better hearing, actively participating in communication). Thus, we argue that hearing-im- paired older adults may be more satisfied with the hearing aids when using the devices in listening situations that are associated with benefits of use.

\section{The Present Study}

This study explores the associations of personal resources and everyday life listening situations with the usage of, and satisfaction with, hearing aids among older adults. A central assumption is that hearing-impaired individuals proactively adapt hearing aid use to the demands of specific listening situations. We examine the extent to which older adults engage in such proactive hearing aid use, how it relates to their usage, and their subjective evaluation of the hearing aids. We assessed intra-individual variability of hearing aid use and hearing quality across everyday situations with an adapted version of the day reconstruction method [18]. We hypothesised that hearing aid use in a greater diversity of listening situations is associated with more positive indicators of hearing aid use. Moreover, we expected that low variability in hearing quality with hearing aids indicates reliable benefits in amplification and therefore positively relates to hearing aid use and satisfaction. These effects are supposed to explain additional variance in positive indicators of hearing aid use compared to common predictors that relate predominantly to personal resources.

We examined positive indicators of hearing aid use on a behavioural and on an evaluative dimension. Empirical data have shown that even satisfied hearing aid owners may use their devices rarely, while in contrast some dissatisfied individuals may use the hearing devices more than $8 \mathrm{~h}$ a day [19]. We argue that efficient hearing aid use involves both using the devices and simultaneously maximising their subjective utility [15]. Describing proactive hearing aid use may contribute to improved understanding of consistency in everyday use and evaluation of the hearing devices.

\section{Methods}

\section{Participants}

Participants responded to personal invitations via online communities and support groups for hearing-impaired individuals as well as to reports in the print media about the study. In total, 158 hearing aid owners ranging in age from 50 to 88 years ( mean $=64.94$, $\mathrm{SD}=9.08)$ participated in the study. The sample included 89 men (56\%). Thirteen percent had completed primary education, $23 \%$ lower secondary education, and $64 \%$ held a high school degree. Seventy-five percent of the participants were married, $10 \%$ were single, and $8 \%$ were divorced or widowed. Most participants were pensioners (58\%), 13\% worked part-time, and 29\% worked full-time. 
93\% of the participants were provided with behind-the-ear hearing aids and $7 \%$ with in-the-ear devices. One third of the participants owned hearing aids that were not older than 2 years; $16.5 \%$ had devices older than 5 years. The mean experience of hearing aid use was 10.67 years $(S D=11.96$; range: $0-51$ ). Binaural fittings were present for $96.5 \%$ of the participants; all participants but one used both hearing aids regularly.

\section{Procedure}

The study was administered online. After an introduction describing the study aims and informing about the confidentiality of the data, participants gave consent to data collection. At first, participants answered questions about their hearing loss and described their actual hearing aids. In a second part, participants reconstructed their use of hearing aids during the preceding day completing an adapted version of the day reconstruction method $[18,20]$. The method combines time-budget and experience sampling methods and has been shown to be robust as it reduces recall biases. Participants reported at what time they got up and went to bed the previous day. Subsequently, participants reported whether, and if so, at what time they have inserted and removed their hearing aids during the previous day. $88 \%$ of the participants inserted their hearing aids once, $9.5 \%$ twice, and $2.5 \%$ three times. Moreover, participants completed questions about each single episode (online suppl. information material; for all online suppl. material, see www.karger.com/ doi/10.1159/000366062). By this means, the method accounts for intraindividual short-term process dynamics of hearing aid use [21]. In a final section of the study protocol, participants responded to items on their satisfaction with and attitudes towards hearing aids, health status, and sociodemographic characteristics.

\section{Measures}

Positive Indicators of Hearing Aid Use

We defined satisfaction with hearing aids as well as daily duration of use as positive indicators of hearing aid use. Satisfaction with hearing aids was measured by the Satisfaction with Amplification in Daily Life scale [22]. The scale is comprised of 15 items which altogether form a global factor for satisfaction with hearing aids. Respondents endorsed items on a 5-point Likert scale, ranging from 'strongly agree' to 'strongly disagree' (Cronbach's $\alpha=$ 0.89 ). We modified response options from the original scale (7-point-Likert scale ranging from 'tremendously' to 'not at all'). Daily duration of use was computed via the proportion of waking time using hearing aids the previous day.

Personal Resources

Personal resources of the participants were assessed via self-reported hearing loss, general health, and positive attitudes towards hearing aids. Subjective hearing loss was measured by a 4 -item version of the Amsterdam Inventory [23]. Participants indicated on a 4-point Likert scale whether they have difficulties hearing in several situations without hearing aids. The scale comprises the listening situations that are mostly impaired by age-related hearing loss (conversation with one person, conversation with a group of people, telephoning, and watching TV). Responses ranged from 'no difficulties' to 'not possible' and internal consistency was good (Cronbach's $\alpha=$ 0.84 ). In earlier lab studies, the measure on subjective hearing loss correlated moderately with PTA thresholds at $0.5,1,2$, and $4 \mathrm{kHz}$ $(\mathrm{n}=54, \mathrm{r}=0.461, \mathrm{p}<0.001)$. General health was assessed via one question on subjective health ('How satisfied are you with your health?') extracted from the WHO quality of life questionnaire [24]. Responses were given on a 10-point Likert scale ranging from 'very dissatisfied' to 'very satisfied'. Positive attitudes towards hearing aids were assessed via a 3-item subscale of the Attitudes towards Loss of Hearing Questionnaire [25] that quantifies negative associations with hearing aids on a 5-point Likert scale. The items were inverted in the present study. Thus, higher values correlate with a more positive attitude. Internal consistency was good (Cronbach's $\alpha=0.77$ ).

\section{Hearing Episodes}

Proactive hearing aid use in everyday life was assessed via the diversity of listening situations with hearing aids and the variability of hearing quality in hearing aid use. Listening situations were defined via everyday activities. Throughout the reconstruction of the preceding day, participants chose from 24 activities in episodes with and without hearing aids. The response options were given in correspondence to the Yesterday Interviews in the Berlin Aging Study [26]; for example, they included household chores, mobility, going on errands, time with others, telephoning, and sports. The diversity of listening situations comprises the number of different activities they have carried out in episodes with hearing aids. Additionally, we asked the participants to evaluate hearing on a 5-point Likert scale (ranging from 'no difficulties hearing at all' to 'a lot of difficulties hearing') during those listening situations they named. The standard deviation of hearing quality over all listening situations indicates the hearing variability in hearing aid use in the present study. For our analyses, we also computed the mean hearing quality in hearing aid use over all listening situations named.

We included age, gender, educational level, and experience in hearing aid use as covariates in our analyses. For experience in hearing aid use, respondents indicated the year they were provided with their first hearing aids.

\section{Statistical Analysis}

First, descriptive statistics and bivariate correlations for hearing aid use and satisfaction with hearing aids, personal resources, and proactive hearing aid use in everyday life were computed. Second, hearing aid use and satisfaction with hearing aids was predicted from personal resources and proactive hearing aid use using two separate regression analyses. In order to illustrate the results, we then compared patterns of proactive hearing aid use across those hearing aid users that reported consistently low or high positive indicators of hearing aid use, as well as participants that were inconsistent in usage behaviour and evaluation using analysis of variance.

\section{Results}

Table 1 shows the descriptive statistics for all variables included in the analyses. The proportion of waking time with hearing aids ranges from 19 to $100 \%$. Most of the participants wore their hearing aids for the main part of the preceding day (mean $=0.84, \mathrm{SD}=0.19)$. Satisfaction with hearing aids was relatively high (mean $=3.08, \mathrm{SD}=$ 0.71). Correlations between positive indicators of hearing aid use and potential predictors are displayed in table 2 . 
Table 1. Descriptive statistics for all variables included in the analyses $(n=158)$

\begin{tabular}{|c|c|c|c|c|c|}
\hline & Range & Mean & Median & SE & $\mathrm{SD}$ \\
\hline Waking time with HA (\%) & $0.19-1$ & 0.84 & 0.91 & 0.02 & 0.19 \\
\hline Satisfaction with HA & $0.73-4$ & 3.08 & 3.20 & 0.06 & 0.71 \\
\hline Hearing loss & $0-12$ & 6.28 & 6.00 & 0.19 & 2.44 \\
\hline Subjective health & $0-9$ & 6.28 & 7.90 & 0.19 & 2.42 \\
\hline Positive attitudes & $0.33-4$ & 3.37 & 3.67 & 0.07 & 0.89 \\
\hline Diversity of listening situations with HA & $1-16$ & 7.90 & 8.00 & 0.25 & 3.09 \\
\hline Variability in hearing quality with HA & $0-2.12$ & 0.52 & 0.50 & 0.04 & 0.44 \\
\hline Mean hearing quality with HA & $0.35-4$ & 3.24 & 3.48 & 0.06 & 0.78 \\
\hline
\end{tabular}

HA = Hearing aids

Table 2. Correlations between positive indicators of hearing aid use, personal resources, and proactive hearing aid use $(\mathrm{n}=158)$

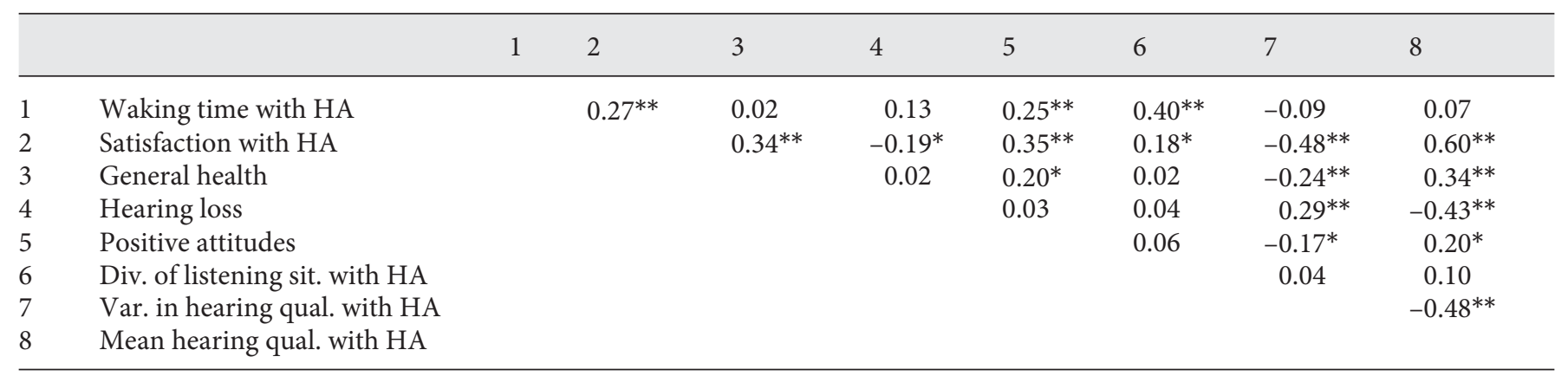

$\mathrm{HA}=$ Hearing aids. ${ }^{*} \mathrm{p}<0.05,{ }^{* *} \mathrm{p}<0.01$

Table 3 displays the results of the multiple regression analyses with waking time and satisfaction with hearing aids as dependent variables. For waking time with hearing aids, no associations were found with general health, hearing loss, and variability in hearing quality with hearing aids. Rather, the results indicate that positive attitudes towards hearing aids $(\beta=0.205, p<0.01)$ as well as the diversity of listening situations $(\beta=0.390, p<0.001)$ relate to longer hearing aid use during waking time (step 1 model; adj. $\left.\mathrm{R}^{2}=0.211, \mathrm{p}<0.001\right)$.

Likewise, satisfaction with hearing aids relates to positive attitudes $(\beta=0.200, p<0.01)$ as well as the diversity of listening situations with hearing aids $(\beta=0.127, \mathrm{p}<$ $0.05)$; and no associations were found with general health and hearing loss. In addition, the variability in hearing quality with hearing aids $(\beta=-0.391, \mathrm{p}<0.001)$ was the best predictor of satisfaction with hearing aids (step 1 model; adj. $\mathrm{R}^{2}=0.470, \mathrm{p}<0.001$ ). This effect also proves robust when controlling for the mean level of hearing quality with hearing aids.

Hearing Aid Use in Everyday Life
To ensure that the effects described above were not the products of demographic or biographical confounds, we repeated the analyses after statistically controlling for age, gender, education, and hearing aid experience. Controlling for these covariates did not alter results (see table 3; step 2 models).

For illustrative purpose, we compared proactive hearing aid use across those hearing aid users that reported consistently low or high positive indicators of hearing aid use, as well as participants that were inconsistent in usage behaviour and evaluation. Approximately one third of the participants $(n=47)$ reported use and satisfaction with hearing aids above the group median. Another $31 \%(\mathrm{n}=50)$ adopted and evaluated their hearing aids below the group median, and $39 \%(n=61)$ reported inconsistent positive indicators of hearing aid use (i.e. low use and high satisfaction with hearing aids). To compare the patterns of proactive hearing aid use across the three subgroups, we computed two ANOVAs with diversity of listening situations and variability in hearing 
Table 3. Associations between personal resources, proactive hearing aid use, and positive indicators of hearing aid use $(\mathrm{n}=158)$

\begin{tabular}{|c|c|c|c|c|c|c|c|c|c|c|}
\hline & \multicolumn{5}{|c|}{ Waking time with HA } & \multicolumn{5}{|c|}{ Satisfaction with HA } \\
\hline General health & & -0.006 & 0.006 & -0.071 & & & 0.029 & 0.019 & 0.098 & \\
\hline Hearing loss & & 0.013 & 0.006 & 0.160 & & & 0.015 & 0.020 & 0.050 & \\
\hline Positive attitudes & & 0.044 & 0.016 & 0.205 & $* *$ & & 0.161 & 0.049 & 0.200 & $* *$ \\
\hline Mean hearing quality with HA & & 0.007 & 0.023 & 0.028 & & & 0.386 & 0.069 & 0.424 & $* *$ \\
\hline Step 2 & 0.229 & & & & & 0.470 & & & & \\
\hline General health & & -0.005 & 0.006 & -0.057 & & & 0.032 & 0.019 & 0.110 & \\
\hline Hearing loss & & 0.009 & 0.007 & 0.109 & & & 0.009 & 0.021 & 0.030 & \\
\hline Positive attitudes & & 0.045 & 0.016 & 0.206 & $* *$ & & 0.169 & 0.049 & 0.211 & $* *$ \\
\hline HA experience & & 0.000 & 0.001 & 0.027 & & & -0.003 & 0.004 & -0.054 & \\
\hline Gender & & -0.008 & 0.029 & -0.020 & & & 0.048 & 0.088 & 0.034 & \\
\hline Education & & 0.002 & 0.009 & 0.018 & & & 0.000 & 0.028 & 0.001 & \\
\hline
\end{tabular}

$\mathrm{HA}=$ Hearing aids. ${ }^{*} \mathrm{p}<0.05,{ }^{* *} \mathrm{p}<0.01$; effects remain stable when controlling for big five personality dimensions (see online suppl. information material; for all online suppl. material, see www.karger.com/doi/10.1159/000366062).

quality with hearing aids as dependant variables. Means were standardised to T-scores. Significant differences between the 3 groups were found for the diversity of listening situations $[\mathrm{F}(2,155)=7.93, \mathrm{p}<0.01]$ and the variability in hearing quality with hearing aids $[\mathrm{F}(2,155)=$ $14.07, \mathrm{p}<0.001$; see fig. 1]. Post hoc analyses revealed that participants with consistently high positive indicators of hearing aid use reported significantly more diverse listening situations with hearing aids (mean $=53.70, \mathrm{SD}=$ 9.25) than those with consistently low positive indicators (mean $=45.99, \mathrm{SD}=9.46)$. Additionally, participants with consistently high positive indicators of hearing aid use indicated significantly less variability in hearing quality with hearing aids $($ mean $=55.27 ; \mathrm{SD}=11.66$ ) than other subgroups (inconsistent positive indicators: mean $=49.22$, $\mathrm{SD}=8.97$; consistently low positive indicators: mean $=45.41, \mathrm{SD}=6.25$ ).

\section{Discussion}

In our research, we found first evidence that hearing aid owners proactively use the hearing devices in response to situation-specific demands and difficulties in hearing qual- ity. We found individual differences in hearing aid use and intraindividual variability in hearing quality with hearing aids across everyday contexts. Such adaptive behavioural patterns relate to positive indicators of hearing aid use. For example, longer and more satisfying hearing aid use was associated with a greater diversity of listening situations, and with experiencing little variability in hearing quality.

Clearly, using hearing aids in everyday life may contribute to improved everyday functioning in hearing impaired individuals [1]. However, our findings also suggest that usage behaviour and satisfaction depend on contextual demands that result from the listening situations of hearing aid use [14]. We contend that hearing aid owners adapt hearing aid use to those contextual demands in accordance with their resources $[15,27]$. In this study, participants named between 1 and 16 different listening situations for hearing aid use. Thus, some participants used their devices selectively in everyday life, whereas others used their hearing aids during most of their activities. The diversity of listening situations with hearing aids was associated with both, duration of use as well as satisfaction with hearing aids.

Additionally, we reported first findings that the subjective hearing quality (while using hearing aids) varies 
Fig. 1. Patterns of proactive hearing aid use across participants with consistent and inconsistent positive indicators of hearing aid use. $\mathrm{HA}=$ Hearing aids. ${ }^{* *} \mathrm{p}<0.01$.

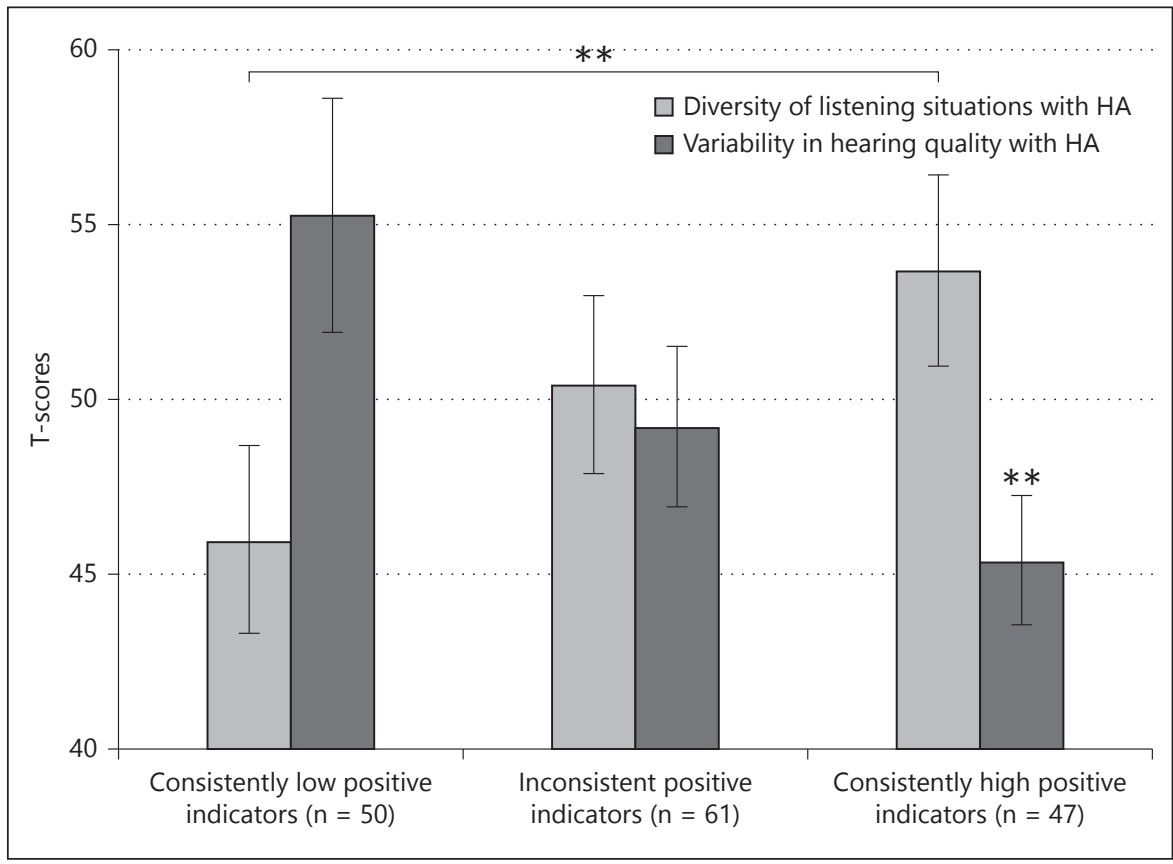

across different activities of the person's preceding day. From this, we conclude that hearing aid use is associated with benefits (i.e. when hearing quality is high), but also with costs (i.e. when hearing quality is low). The variability of hearing quality relates to the subjective evaluation of hearing aids, irrespective of whether the individual's average hearing quality is high or low. Hearing-impaired older adults were more satisfied with the hearing aids when they were more likely to choose to use the devices in listening situations associated with benefits of use. Accordingly, consistent benefits of hearing aid use, as reflected via low variability in hearing quality with hearing aids, relate to higher satisfaction.

Findings may be discussed in the context of positive aging theories, such as the model of selection, optimisation, and compensation $[27,28]$. The model describes adaptive processes of how individuals orchestrate their resources to maximise gains and minimise losses over the lifespan. For example, in response to losses, individuals select more meaningful goals, optimise or maintain their resources needed to achieve those goals, and compensate with new technologies, alternative means or new resources. Consistent with this model, our findings suggest that positive outcomes of hearing aid use not only pertain to the compensatory effect of adopting the hearing devices, but may also involve selection (of listening situations) and optimisation (of usage behaviour) [15]. In the present study, hearing aid use and satisfaction were highest

Hearing Aid Use in Everyday Life for those individuals who managed diverse demands of listening situations in maintaining a high and stable level of hearing quality with hearing aids.

Clearly, hearing-impaired individuals strive to hear better. Using hearing aids does not necessarily constitute a conscious or intentional process of action regulation. We argue that hearing aid use in everyday life might be associated with automated behaviours (i.e. routines). Both processes reflect behavioural adaptations that relate to improved outcomes of hearing aid use (i.e. longer duration of use, more satisfaction, better hearing). Further experimental research will have to determine to which degree the proactive behaviours described in the present study are subject to intentional or automated processes.

The analyses included behavioural and evaluative indicators of hearing aid use as distinct measures. The results revealed different prediction models for the two measures. Additionally, patterns of proactive hearing aid use differed between participants that reported consistently high positive indicators of hearing aid use (high usage, high satisfaction) and those that reported low or inconsistent positive indicators. Future research may consider an integrative indicator of efficient hearing aid use that refers to using the devices while maximising their subjective benefit, for example, with regard to feeling satisfied [15].

These findings underline that individual differences in daily hearing aid use and hearing quality should be con- 
sidered in hearing aid fitting and counselling. We further investigated the listening situations that the participants named in episodes with and without hearing aids. The results reveal that hearing aid use differs significantly for a number of instrumental activities of daily living, such as shopping, going on errands, and outdoor mobility, as well as activities that require communication (i.e. telephone, time with others). Hearing aid use is also more frequent for activities that are addressed by a special configuration of the hearing aids, such as watching television and listening to music. Nevertheless, there was no difference in hearing aid use for leisure activities at home (i.e. reading, creative activity, computer use). The findings support the theory that hearing-impaired individuals proactively use their hearing aids in response to everyday life contexts.

The present findings are based on a correlational study. Therefore, our data do not allow inferring the direction of effects from proactive hearing aid use on usage of and satisfaction with hearing aids. We submit that our findings justify further research to test such hypotheses with longitudinal study designs. Additionally, more measurement occasions will have to be implemented in order to better understand the adaptive processes in the daily patterns of hearing aid use. For example, studying the first months after initial hearing aid provision would allow differentiation between those older adults that easily or hardly adapt to hearing aid use in everyday life.

Finally, we acknowledge several limitations in the study. First, the sample was selective with respect to Internet use and educational status. Thus, future research needs to replicate these findings with different subgroups of older adults that are, for example, not familiar with the
Internet. As the sample was composed of hearing aid owners, we premised that all participants had clinical hearing impairment. Future studies should account for hearing thresholds measured via pure tone audiograms as well as non-auditory capacities, such as fine motor skills and cognition $[6,7]$. In our study, we defined and operationalised environmental demands via listening situations of hearing aid use. Future research should also consider the demands that result from the design and configuration of the hearing aid devices. There is empirical evidence showing that configurations of the hearing aids differentially fit specific personal demands. For example, older adults with reduced cognitive abilities were found to obtain greater benefits from hearing aids with slowacting compression [29].

In conclusion, our findings suggest that hearing aid owners contribute to positive outcomes of hearing aid use in everyday life in response to situation-specific demands and difficulties regarding hearing quality. Individuals who reported high and satisfying hearing aid use were characterised by managing diverse demands of listening situations while experiencing low variability in hearing quality. Future research, as well as audiologists in the field, should account for those adaptive competences as well as situation-specific demands within and across hearing aid owners.

\section{Acknowledgement}

We thank Anja Beyer, Lucas Wolski, and Kathrin Holthoff for their support in data collection and Stefan Kamin for his valuable comments on earlier versions of the manuscript.

\section{References}

1 Tesch-Römer C: Psychological effects of hearing aid use in older adults. J Gerontol B Psychol Sci Soc Sci 1997;52B:127-138.

2 Hartley D, Rochtchina E, Newall P, Golding M, Mitchell P: Use of hearing aids and assistive listening devices in an older Australian population. J Am Acad Audiol 2010;21:642653

3 Bertoli S, Staehelin K, Zemp E, Schindler C, Bodmer D, Probst R: Survey on hearing aid use and satisfaction in Switzerland and their determinants. Int J Audiol 2009;48:183-195.

4 Hougaard S, Ruf S: EuroTrak I: A consumer survey about hearing aids in Germany, France, and the UK. Hear Rev 2011;18:12-28.

5 Uriarte M, Denzin L, Dunstan A, Sellars J, Hickson L: Measuring hearing aid outcomes using the Satisfaction with Amplifi- cation in Daily Life (SADL) questionnaire: Australian data. J Am Acad Audiol 2005; 16 : 383-402.

6 Erber NP: Use of hearing aids by older people: influence of non-auditory factors (vision, manual dexterity). Int J Audiol 2003;42:2125.

7 Lunner T: Cognitive function in relation to hearing aid use. Int J Audiol 2003;42(suppl 1): s49-s58.

8 Wilson C, Stephens D: Reasons for referral and attitudes toward hearing aids: do they affect outcome? Clin Otolaryngol 2003;28:8184.

9 Wiesner M, Tesch-Roemer C: Hörgerätebenutzung im Alter: Der Zusammenhang zwischen Intention und Verhalten. Z Gerontol Geriatr 1996;29:273-279.
10 Takahashi G, Martinez CD, Beamer S, Bridges J, Noffsinger D, Sugiura K, Bratt GW, Williams DW: Subjective measures of hearing aid benefit and satisfaction in the NICDCD/VDA follow-up study. J Am Acad Audiol 2007;18: 323-349.

11 Saunders GH, Jutai JW: Hearing specific and generic measures of the psychosocial impact of hearing aids. J Am Acad Audiol 2004;15: 238-248.

12 Cox RM, Alexander GC, Gray GA: Personality, hearing problems, and amplification characteristics: contributions to self-report hearing aid outcomes. Ear Hear 2007;28:141162.

13 Li-Korotky HS: Age-related hearing loss: quality of care for quality of life. Gerontologist 2012;52:265-271. 
14 Wong LLN, Hickson L, McPherson B: Hearing aid satisfaction: what does research from the past 20 years say? Trends Amplif 2003;7: 117-161.

15 Williger B, Lang FR: Managing age-related hearing loss: how to use hearing aids efficiently. Gerontology 2014;60:440-447.

16 Hallberg LRM, Erlandsson SI, Carlsson SG: Coping strategies used by middle-aged males with noise-induced hearing loss, with and without tinnitus. Psychol Health 1992;7:273-288.

17 Melenhorst A-S, Rogers WA, Bouwhuis DG: Older adults' motivated choice for technological innovation: evidence for benefit-driven selectivity. Psychol Aging 2006;21:190-195.

18 Kahneman D, Krueger AB, Schkade DA, Schwarz N, Stone AA: A survey method for characterizing daily life experience: the day reconstruction method. Science 2004;306: 1776-1780.

19 Laplante-Levesque A, Knudsen LV, Preminger JE, Jones L, Nielsen C, Oberg M, Lunner T, Hickson L, Naylor G, Kramer SE: Hearing help-seeking and rehabilitation: perspectives of adults with hearing impairment. Int $\mathrm{J} \mathrm{Au}$ diol 2012;51:93-102.
20 John D: Subjective acceleration of time in older adults' everyday life: motivation matters; $\mathrm{PhD}$ thesis, Erlangen, 2014.

21 Hamaker E: Why researchers should think 'within-person': a paradigmatic rationale; in Mehl MR, Conner TS (eds): Handbook of Methods for Studying Daily Life. New York, Guilford Publications, 2012, pp 43-61.

22 Cox RM, Alexander GC: Validation of the SADL questionnaire. Ear Hear 2001;22:151160.

23 Kramer SE, Kapteyn TS, Festen JM, Tobi H: Factors in subjective hearing disability. Audiology 1995;34:311-320.

24 Angermeyer MC, Kilian R, Matschinger H: Deutschsprachige Version der WHO Instrumente zur Erfassung von Lebensqualität WHOQOL-100 und WHOQOL-bref. Göttingen, Hogrefe, 2000.
25 Saunders GH, Cienkowski KM, Forsline A, Fausti S: Normative data for the attitudes towards loss of hearing questionnaire. J Am Acad Audiol 2005;16:637-652.

26 Baltes MM, Maas I, Wilms H-U, Borchelt M, Little TD: Everyday competence in old and very old age: theoretical considerations and empirical findings; in Baltes $\mathrm{PB}$, Mayer KU (eds): The Berlin Aging Study: Aging from 70 to 100. Cambridge, University Press, 1999, pp 384-402.

27 Baltes MM, Carstensen LL: The process of successful ageing. Ageing Soc 1996;16:397422.

28 Baltes PB, Baltes MM: Psychological perspectives on successful aging: the model of selective optimization with compensation; in Baltes $\mathrm{PB}$, Baltes MM (eds): Successful Aging: Perspectives from the Behavioral Sciences. New York, Cambridge University Press 1990, pp 1-34.

29 Gatehouse S, Naylor G, Elberling C: Benefits from hearing aids in relation to the interaction between the user and the environment. Int J Audiol 2003;42:77-85. 